\title{
UNIQUE FIVE VESSEL PATTERN OF HUMAN AORTIC ARCH: A CASE
} REPORT

\section{Dolly ${ }^{* 1}$, C.S. Ramesh Babu ${ }^{2}$, Vishnu Gupta ${ }^{3}$, Sudhir Sachar ${ }^{4}$.}

${ }^{* 1}$ P.G. Resident, Department of Anatomy, Muzaffarnagar Medical College, Muzaffarnagar, (U.P.), India.

${ }^{2}$ Associate Professor, Department of Anatomy, Muzaffarnagar Medical College, Muzaffarnagar, (U.P.), India.

${ }^{3}$ Professor and Head, Department of Anatomy, Muzaffarnagar Medical College, Muzaffarnagar, (U.P.), India.

${ }^{4}$ Professor and Head, Department of Radiodiagnosis, Muzaffarnagar Medical College, Muzaffarnagar, (U.P.), India.

\section{ABSTRACT}

We report here a unique vascular pattern of left sided aortic arch, detected incidentally in a 55 year old female, who underwent CECT chest for symptom of chronic cough. There were five vessels arising from the convex aspect of the arch with sequence as right common carotid artery (RCCA), left common carotid artery (LCCA), left vertebral artery (LVA), left subclavian artery (LSA) and aberrant right subclavian artery (ARSA).

KEY WORDS: Aortic arch anomalies, Aberrant right subclavian artery, aortic origin of left vertebral artery.

Address for Correspondence: Dr. Dolly, P.G. Resident, Department of Anatomy, Muzaffarnagar Medical College, NH -58, opposite Begrajpur Industrial Area, Muzaffarnagar (U.P.), Pin- 251203 E-Mail: pathfinderdg81@gmail.com

Access this Article online

Quick Response code

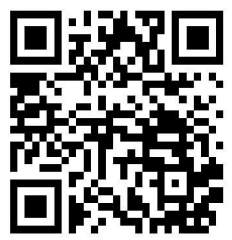

DOI: $10.16965 /$ ijar.2018.421



\section{INTRODUCTION}

A classical left sided aortic arch gives rise to three vessels from its convex aspect with sequence as brachiocephalic trunk (BT), left common carotid artery (LCCA), left subclavian artery (LSA) and was first classified as type I by Adachi [1]. This typical three vessel pattern has a prevalence of $65 \%-87.4 \%$ [1-4] in different populations across the world. Remaining $12.6 \%-35 \%$ of the population shows a great variety of branching patterns, commonest being a two vessel pattern with a common trunk of BT and LCCA, classified as type II by Adachi and has been widely referred as Bovine aortic arch in literature. Adachi type III refers to a variant arch with four vessels with arch origin of LVA between LCCA and LSA.

Complex development of aortic arch and its branches leads to a wide range of vascular patterns, as mentioned in the literature. As most of them are asymptomatic, they are detected as incidental findings during cadaveric dissection, imaging studies or surgeries. However, non recognition of a variant arch anatomy can have fatal outcomes in setting of an urgent cardiothoracic surgery which may be required for cases 
of aortic dissection, aortic aneurysm and traumatic injuries of thoracic and neck regions.

\section{CASE REPORT}

Present variation pertaining to branching pattern of the aortic arch was observed in a 55 year old female who underwent CECT of chest for symptom of chronic cough. Though there was no lung pathology which could give rise to her symptoms, attention was drawn to the presence of an anomalous branching pattern of the normal left sided arch. The aortic arch was giving origin to five first degree supraaortic branches instead of the classical three vessels. Brachiocephalic trunk was absent leading to arch origin of RCCA and RSA, as first and last branches respectively. As distal most branch of the arch, RSA was having an anomalous or aberrant course to reach its destination in right arm. It was crossing the midline by running between the oesophagus and vertebral column (retroesophageal course). An additional vessel of smaller diameter identified as LVA was arising between origins of LCCA and LSA. These five vessels were arranged in sequence of RCCA, LCCA, LVA, LSA, aberrant RSA [Fig.1].

Fig. 1: Axial (a), coronal (b) and volume rendered (c-d) MDCT images of a patient showing a unique vascular pattern with five vessels (1-5). 1) Rt. Common Carotid A. 2) Lt. Common Carotid A. 3) Lt. Vertebral A. 4) Lt. Subclavian A. 5) Retroesophageal Rt. Subclavian A.
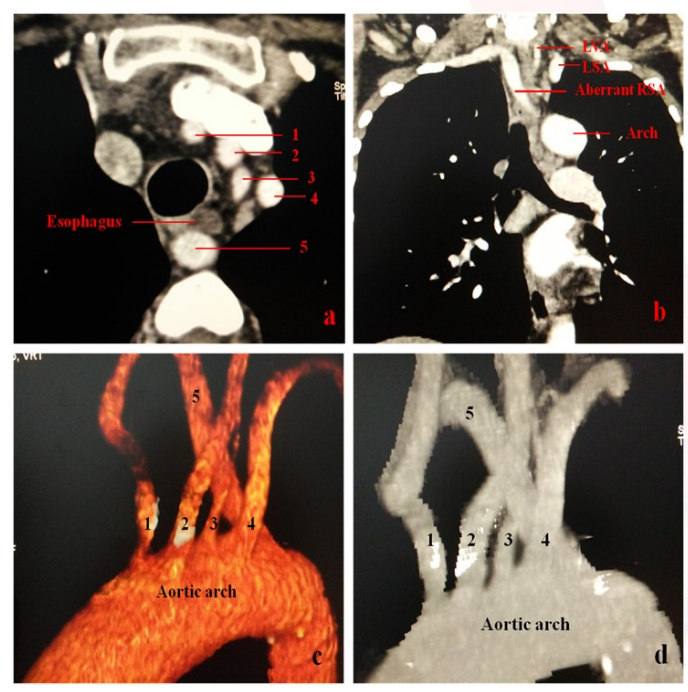

\section{DISCUSSION}

Variations in the branching pattern of aortic arch are not infrequent and have a prevalence of $12.6 \%-35 \%$. A number of variations are mentioned in literature but only few of them are common. The "two vessel pattern" with sharing of BT and LCCA and presence of LSA as second vessel is the most common variant pattern and has a prevalence of $7.2 \%-27.1 \%$ [1-4]. The second common variant is arch origin of LVA between LCCA and LSA as a four vessel pattern and has prevalence of $0.8 \%-4.3 \%$ [1-4].

The aberrant RSA (ARSA) without any other associated anomaly as a four vessel pattern with sequence as "RCCA, LCCA, LSA, ARSA" has been reported in literature with a frequency rate of $0.4 \%-2 \%$ [5-6]. ARSA is the name given to RSA arising as distal most branch of the arch and running an aberrant course from left to right, crossing the midline either in retro-oesophageal plane $(80 \%)$ or between oesophagus and trachea (15\%) or anterior to trachea (5\%) [5-6].

ARSA as observed in the present case with arch origin of LVA with the sequence as RCCA, LCCA, LVA, LSA, ARSA has been rarely reported in the literature. Ramesh babu et al [7] mentioned a similar five vessel pattern of left sided arch but associated with heterotaxy polysplenia syndrome.

ARSA has also been observed in association with the presence of bicarotid trunk or vertebro - subclavian trunk or both or with the absence of LCCA to give rise unique vascular patterns as Bicarotid trunk, LSA, ARSA [6,8]; RCCA, Left internal carotid (LICA), left external carotid (LECA), LSA, ARSA [8]; Bicarotid trunk, Vertebro-subclavian trunk, ARSA [9].

Generally ARSA is asymptomatic. However, in elderly patients an anomalous right subclavian artery occasionally becomes tortuous and can compress the trachea or oesophagus causing dyspnoea or dysphagia respectively [10].

Dysphagia is more likely to occur if the origin of the artery undergoes isolated aneurysmal dilatation. This entity is specifically known as a "diverticulum of Kommerell" named after the German radiologist who first recognized this on barium meal test [11].

Dysphagia caused by a vascular ring is called as "dysphagia lusoria" and artery causing it is known as "arteria lusoria". Thus, Aberrant RSA is also known as arteria subclavia dextra lusoria (ASDL). Intensive care patients should be screened for ASDL before long term placement 
of nasogastric tube in order to avoid fistulization and fatal hemorrhage [12].

Arch anatomy should be evaluated for presence of retroesophageal RSA before performing oesophagectomy, which may be required in diseases such as oesophageal cancers. Prior knowledge of this variant anatomy allows the surgeon to take caution while clearing retroesophageal space. Also, in cases of dysphagia with associated oesophageal cancer and ASDL, it is difficult to ascertain whether dysphagia is due to the cancerous mass or ASDL.

The aberrant RSA is also accompanied with variation in the course of right recurrent laryngeal nerve. As it cannot form a loop around RSA, it goes straight to supply the larynx and is called "nonrecurrent laryngeal nerve [3]. The above unusual position of the nerve can lead to a surgical hazard during thyroidectomy and tracheostomy.

LVA of arch origin also has its own clinical implications. It is hypothesized that, such anomalous origin increases blood flow in the left vertebral artery. This direct (straight line) flow of blood from aorta to brain or imbalance of flow of blood on left and right sides may lead to altered hemodynamics at circle of Willis [13] and can predispose patient to intracranial aneurysms. Satti et al [14] claimed that patients with such anomalies should therefore be screened for coexisting aneurysms. However, within the current literature, there is no conclusive evidence to suggest that anomalous origin of the vertebral arteries predisposes an individual to cerebrovascular disorders [15].

The prevertebral segment of such anomalous LVA has frequently been observed to be affected by atherosclerosis [13]. This variant is also associated with significantly higher incidence of vertebral artery dissection than LVA of subclavian artery origin [16].

The LVA of arch origin can be diagnosed only in $40 \%$ of the cases [13]. Being smallest in diameter, it is obscured by other larger branches arising from the arch making its preoperative detection by radiology more difficult.

Embryologically, arch of aorta and its branches are derivatives of six pairs of pharyngeal arch arteries which appear symmetrically connecting the right and left limbs of the aortic sac to the right and left dorsal aortae which fuse to form a single median descending aorta just caudal to fourth thoracic segment. With further development, aortic arch system loses its original symmetrical form and transformed in to an adult arterial pattern.

The possible embryological basis of origin of anomalous RSA is the early involution of right fourth aortic arch and cranial part of right dorsal aorta with its consequent development from the right seventh intersegmental artery and from the distal segment of the right dorsal aorta. Later on, differential growth shifts the origin of RSA closer to the LSA [6].

Normally, first part of LVA develops from the dorsal ramus of left seventh intersegmental artery, which itself give rise to LSA. The possible embryologic explanation of direct arch origin of LVA is: persistence of left 6th intersegmental artery with a segment of left dorsal aorta and regression of dorsal branch of left 7th intersegmental artery. This variation can also be explained as incorporation of proximal part of left 7th intersegmental artery (prior to its dorsal branch) into the developing arch of aorta [7].

\section{CONCLUSION}

Variations in the branching pattern of the aortic arch are prevalent with a substantial frequency of $12.6 \%-35 \%$. Most of them are asymptomatic and remain silent throughout the life. But when a surgical intervention is required in thorax and neck region, their prior evaluation and knowledge is of critical importance

\section{Conflicts of Interests: None}

\section{REFERENCES}

[1]. Adachi B: Das arteriensystem der Japaner. Vol 1. $1^{\text {st }}$ ed. Verlag der Kaiserlich-Japanichen Universitat, Kenyusha Press, Kyoto 1928;22-43.

[2]. Anson (1963) cited in Gray's Anatomy: The Anatomical basis of clinical practice 39th ed.Edinberg: Churchill Livingstone; 2005;1021-1022.

[3]. Lale P, Toprak U, Yagiz $G$ et al: Variations in the branching pattern of aortic arch detected with computerized tomography angiography. Advances in Radiology 2014. [http://dx.doi.org/10.1155/2014/ 969728] 
[4]. Natsis KI, Tsitouridis IA, Didagelos MV, Fillipidis AA, Vlasis KG, Tsikaras PD: Anatomical variations in the branches of the human aortic arch in 633 angiograpahies: clinical significance and literature review. Surgical and Radiological Anatomy 2009;31:319-323.

[5]. Bergman RA, Afifi AK, Miyauchi R: Illustrated encyclopedia of human anatomic variation.[http:// www.anatomyatlases.org/AnatomicVariants/Cardiovascular/Text/Arteries/Aorta.shtml]

[6]. Mligiliche NL, Isaac ND: A three branches aortic arch variant with a bi-carotid trunk and a retroesophageal right subclavian artery. IJAV 2009;2:1114.

[7]. Ramesh Babu CS, Gupta KK, Qasim M, Gupta OP. Heterotaxy Polysplenia syndrome in an adult with unique vascular anomalies: Case report with review of literature. Radiology Case (JRCR); 2015; 9(7): 22-37.

[8]. Acar M, Ulusoy M, Zararsiz I, Efe D. Anatomical variations in the branching of human aortic arch. Biomed Res- India 2013;24(4):531-535.

[9]. Gluncic V, Ivkic G, Marin D, Percac S: Anomalous origin of both vertebral arteries. Clin Anat. 1999;12(4):281-84.

[10]. Kieffer E, Bahnini A, Koskas F: Aberrant subclavian artery: surgical treatment in thirty-three adult patients. J. Vasc. Surg. 1994;19:100-109.
[11]. Van Son JAM, Konstantinov IE, Burckhard F: Kommerell and Kommerell's diverticulum. Tex Heart Inst J 2002;29:109-12.

[12]. Fazan VPS, Ribeiro RA, Ribeiro JAS, Rodrigues Filho OA: Right retroesophageal subclavian artery. Acta Cir Bras 2003;18:54-6.

[13]. Ughade JM, Kardile PB, Ughade MN, Chaware PN, Pandit SV: Anomalous arch of aorta giving rise to left vertebral artery. Int J Biol Res 2012;3(4):245254.

[14]. Satti SR, Cerniglia CA, Koenigsberg KA: Cervical vertebral artery variations: an anatomic study. American Journal of Neuroradiology 2007;28(5):976-80.

[15]. Albayram S, Gailloud P, Wasserman BA: Bilateral arch origin of the vertebral arteries. AJNR Am J Neuroradiol 2002;23(3):455-8.

[16).Komiyama M, Morikawa T, Nakajima H, Nishikawa $M$, Yasui T: High incidence of arterial dissection associated with left vertebral artery of aortic origin. Neurol med chir (Tokyo) 2001;41:8-12.

\author{
How to cite this article: \\ Dolly, C.S. Ramesh Babu, Vishnu Gupta, Sudhir Sachar. UNIQUE \\ FIVE VESSEL PATTERN OF HUMAN AORTIC ARCH: A CASE REPORT. \\ Int J Anat Res 2019;7(1.1):6128-6131. DOI: 10.16965/ijar.2018.421
}

